\title{
Assessing how a tobacco-free campus leads to attitude change and support among students, faculty, and staff
}

\author{
Trevin E. Glasgow ${ }^{1,2}$, Carrie A. Miller ${ }^{1}$, D. Jeremy Barsell', Elizabeth K. Do ${ }^{1,2}$, Bernard F. Fuemmeler ${ }^{1}$
}

\begin{abstract}
INTRODUCTION Universities are increasingly considering tobacco-free campus policies to help promote a healthy learning and working environment. We assessed attitudes of students, faculty, and staff, before and after the implementation of a tobacco-free campus policy at a large, urban university. We also examined individual factors associated with these attitudes.

METHODS An independent panel design method was used to assess students, faculty and staff about their tobacco product use, attitudes towards tobacco policies, and support for cigarette and e-cigarette bans 3 months before and 7 months after a university-wide policy change to ban tobacco and e-cigarettes on campus. Survey participants before the policy change included 636 students and 1356 faculty/ staff. Survey participants after the policy change included 1000 students and 574 faculty/staff. We conducted separate multiple linear and logistic regression models for students and faculty/staff.

RESULTS Attitudes towards tobacco-free campus policies did not improve for students, but did for faculty/staff. Support for bans of cigarettes and e-cigarettes on campus increased following the policy change among both students and faculty/staff. Students were more willing to ask their friends to stop vaping post-policy, but did not differ in their willingness to ask friends to stop smoking. Among the individual factors considered, gender and use of cigarettes and e-cigarettes were predictive of attitudes among both students and faculty/staff. Women were more likely to support and have more positive attitudes towards bans, while current tobacco product users were less likely to support tobacco product bans and have less positive attitudes towards tobacco policies.

conclusions Attitudes towards tobacco-free campus policies changed pre- to postpolicy among faculty/staff, but not among students. However, both students and faculty/staff were more supportive of tobacco product bans following the policy change. Individual factors associated with support and attitudes were identified.
\end{abstract}

\section{AFFILIATION \\ 1 Department of Health Behavior and Policy, Virginia Commonwealth University, Richmond, United States 2 Department of Epidemiology, Milken Institute School of Public Health, George Washington University, Washington, United States \\ CORRESPONDENCE TO \\ Trevin E. Glasgow. Department of Health Behavior and Policy, Virginia Commonwealth University, 830 E. Main Street, Richmond, VA 23219, United States. Email: trevin. glasgow@vcuhealth.org ORCID ID: https://orcid.org/0000- 0001-6699-8983}

\section{KEYWORDS}

tobacco policies, tobacco-free, attitudes, college students, university faculty, tobacco bans

Received: 8 April 2021 Revised: 21 May 2021

Accepted: 26 May 2021

\section{INTRODUCTION}

The transition to college life may increase young adults' risk of developing substance use problems, including tobacco use $\mathrm{e}^{1-3}$. Colleges and universities have taken steps to discourage or eliminate the use of tobacco products on campus through the implementation of tobacco-free policies ${ }^{4-6}$. Such policies have the potential to improve campus life, by not only discouraging tobacco use among young adults but also reducing secondhand smoke exposure, improving the aesthetics of campus by reducing tobacco litter, and creating a culture of health on campus. A recent metaanalysis found a majority of students support tobaccofree policies ${ }^{6}$, and as bans on tobacco use have been 
increasing in public places, including high schools, college-bound students are expecting their college of choice to also be tobacco-free.

While most college and university campuses have a ban on indoor tobacco use, including combustible and non-combustible tobacco, banning the use of tobacco both inside and outside on campus is not universally adopted. A recent challenge to universities adopting a tobacco-free campus has been the rapidly evolving tobacco product landscape. The use of e-cigarettes or waterpipe tobacco use has increased among college-age youth. Studies show that young adults are more accepting of the use of e-cigarettes in public places compared to traditional cigarettes $^{7}$. College students have more positive perceptions towards waterpipe use compared to cigarettes $^{8}$. Thus, a critical component to addressing changes in campus tobacco polices is to understand the attitudes and behaviors of students toward policies that address all forms of tobacco use.

To help better understand the impact or consequence of tobacco-free campus policies, a growing number of studies have assessed attitudes and support either before or after the implementation of a tobaccofree campus policy. Prior to the implementation of a tobacco policy at a university in the United Kingdom, almost $70 \%$ of students and staff supported a tobaccofree campus ${ }^{9}$. Interestingly, less than half of participants supported a ban of e-cigarettes. Lechner et al. ${ }^{10}$ measured changes in attitudes before and after the implementation of a university tobacco ban and found students reported an increased preference to be in a smoke-free environment and increased support in the enforcement of the ban.

While attitudes and support of proposed tobacco-free policies are important outcomes to measure when developing a tobacco-free campus environment, enforcement strategies such as willingness to approach violators of the policy should also be considered. Gatto et al. ${ }^{11}$ found that many university members felt uncomfortable approaching violators of the policy after the implementation of a tobacco-free campus policy at the University of South Florida as they thought it could upset the violators. Additionally, only $10 \%$ of violators of a tobaccofree policy at the University of Mississippi reported receiving a warning or fine for their violation ${ }^{12}$. Respondents in the study felt that there was a lack of support from the university community, which contributed to the frequent violations. Limitations of these prior studies include a lack of faculty/staff ${ }^{10,12}$ or including faculty/staff, but not measuring attitudes among the university members ${ }^{11}$.

However, not everyone has positive attitudes towards policies and not everyone is supportive of tobacco policies. Individual factors such as sociodemographic differences and peer influence ${ }^{13}$ have been shown to influence one's support and attitudes towards tobacco policies. Support for smoking bans has been shown to be higher among non-smokers compared to smokers ${ }^{9}$. Non-smokers on campus also perceive the harms of smoking to be greater and hold stronger attitudes towards implementing tobacco-free policies ${ }^{14}$. Men have been shown to support tobacco policies less than women ${ }^{15,16}$ and older individuals have been found to hold more favorable views towards tobacco policies ${ }^{17,18}$.

The current study expands upon our prior research conducted on students' attitudes towards tobacco-free policies before implementation of a tobacco-free policy. Using mixed-methods, the majority of students agreed that colleges have a responsibility to adopt tobacco-free policies that reduce the risk of tobacco addiction and identified e-cigarettes as a unique obstacle to tobacco-free policies ${ }^{19}$. The present study expands upon this research and the extant literature with the following three aims:

- Aim 1 - Assess the change in attitudes towards tobacco policies, support for tobacco product bans, and exposure to secondhand smoke before and after the implementation of a tobacco-free campus policy;

- Aim 2 - Assess how individual factors (e.g. age, gender, race/ethnicity) influence attitudes, support for tobacco bans, and exposure to secondhand smoke; and

- Aim 3 - Assess college student willingness to ask peers to stop using tobacco products before and after the policy implementation.

\section{METHODS}

\section{Participants and procedure}

Three months prior to the implementation of a tobacco-free campus policy at a large, urban university in the Mid-Atlantic US, students and faculty/staff were contacted to complete a survey 
through REDCap, a web application that can be used to develop and administer surveys ${ }^{20,21}$. The policy banned tobacco products of all types on college grounds inside and outside, with a number of limited designated smoking areas allowed. The research team contracted with a university-affiliated research group to enroll participants and distribute the survey. A disproportionate stratified random sampling design was used to select a representative subset of the university's student and faculty/staff population. The survey consisted of demographic questions alongside questions related to tobacco. Seven months following the implementation of the policy (i.e. after July 2019, 'post-policy'), a new set of participants were contacted to complete the same survey that the prepolicy group had completed. The study procedures were determined to be exempt from the university's Institutional Review Board, provided the data were collected anonymously from participants.

To be eligible to participate in the study, participants needed to be aged $\geq 18$ years and either currently enrolled or employed at the university. A total of 3566 students and faculty/staff from the university participated in the study, consisting of $1636(45.9 \%)$ students and 1930 (54.1\%) faculty/ staff. Specifically, 636 students and 1356 faculty/ staff completed the survey prior to the policy implementation. After policy implementation, 1000 students and 574 faculty/staff completed the survey.

\section{Measures}

Opinion on the best tobacco policy for campus

Using measures from the Georgia Tobacco-Free Colleges and Universities Toolkit ${ }^{22}$, students and faculty/staff were asked which tobacco policy would be best for the campus and given a choice of four policies. For cigarettes and e-cigarettes separately, respondents were queried for their opinion of the following policy options: 'Prohibit use indoors and outdoors at all times', 'Prohibit use indoors; Allow use outdoors in specific locations only', 'Prohibit use indoors; Allow use outdoors everywhere', and 'Allow use indoors and outdoors everywhere'. To be consistent with the policies of current universities aiming to become tobacco-free, respondents who selected either 'Prohibit use indoors and outdoors at all times' or 'Allow use outdoors in specific locations only' were considered to be in support of either a cigarette or e-cigarette ban. The other two responses were considered as not being in support of a ban.

\section{Attitudes towards tobacco policies}

Students and faculty/staff indicated their agreement with five statements: 1) 'Colleges have a responsibility to reduce the risk of tobacco addiction by adopting policies that discourage tobacco product use'; 2 ) 'Colleges have a responsibility to adopt policies that ensure people have smoke-free air to breathe'; 3 ) 'Colleges should not allow tobacco companies to promote product use on campus through advertising, sponsorship of student events, and/or financial support of student organizations'; 4) 'A campus free of cigarette litter is important to me'; and 5) 'It is the responsibility of each university community member to follow the policies and regulations regarding smoking and tobacco use on campus'. Respondents answered using a 5-point Likert scale ranging from 'Strongly disagree (1)' to 'Strongly agree (5)'. Reliability of the five items was acceptable (Cronbach's $a=0.82$ for students and 0.79 for faculty/staff). A composite score was created by calculating the average of the five items and used for all analyses, with higher scores indicating higher support for tobacco policies. These measures were obtained from the Georgia TobaccoFree Colleges and Universities Toolkit ${ }^{22}$.

\section{Secondhand smoke exposure}

Students and faculty/staff reported their exposure to secondhand smoke with the following question: 'When I am on campus, I am exposed to secondhand smoke' and responded with one of the following answers on a 5-point scale: 'Never (1)', 'Rarely (2)', 'Sometimes (3)', 'Often (4)', and 'Always (5)'. This variable was not dichotomized in order to assess level of exposure and to provide more granularity in results. Higher scores indicate greater secondhand smoke exposure.

\section{Current cigarette and e-cigarette use}

Students and faculty/staff were asked about their current cigarette use with the following question: 'Do you now smoke cigarettes every day, some days, or not at all?'. Respondents responded with 'Every day,' 'Some days,' or 'Not at all'. Responses were dichotomized ('No'='Not at all'; 'Yes'='Every day'/'Some days'). Since non-tobacco or non-cigarette users did not see this question, they were also coded 
as 'No'. For e-cigarette use, participants answered the following question: 'During the past 30 days, on how many days did you use Electronic Nicotine Products? If none, please type 0'. Respondents that provided a value not equal to 0 were coded as 'Yes' for current e-cigarette user and 'No' if they chose 0 . Since non-tobacco users did not see this question, they were also coded as 'No'. Although participants also answered questions on smokeless tobacco use, very few students and faculty/staff actually used these products. Therefore, smokeless tobacco use was not included in the analyses.

\section{Peer cigarette use and vaping}

Only students were asked: 'How many of your friends smoke cigarettes?' and 'How many of your friends vape?'. Respondents answered with four possible answers: 'None', 'A few', 'Most of them', or 'All of them ${ }^{\prime 13}$. Responses were dichotomized as: 'No'='None' or 'Yes'='A few'/'Most of them'/'All of them'.

\section{Willingness to stop friends from smoking or vaping} Only students were asked: 'How much would you try to stop your friends from smoking cigarettes?' and 'How much would you try to stop your friends from vaping?'. Respondents answered with four possible answers: 'Not at all', 'Not much', 'Some', and 'A lot'. Responses were dichotomized as: 'Would not stop'='Not at all'/'Not much' or 'Would stop'= 'Some'/'A lot'.

\section{Statistical analysis}

Multiple linear regression was performed to identify predictors of attitudes and support related to tobacco policies on a college campus. Our predictors of interest included in the models for both students and faculty/staff were time of survey completion (pre- vs post-policy implementation) as well as demographic characteristics, cigarette smoking status, and e-cigarette smoking status. Whether friends smoke and vape were also included for student models. Employee classification (faculty or staff) was included as a predictor in employee models. With the exception of the continuous measurement of age, all variables entered into the models were binary categorical variables. We also conducted several logistic regression models to identify predictors of support for policy bans and willingness to approach smokers and vapers (students only). The same predictors used for the attitudes were included in the logistic regression models. $\mathrm{R}$ statistical software was used for all statistical analyses.

\section{RESULTS}

\section{Descriptive statistics}

Complete descriptive statistics of students and faculty/ staff are provided in Tables 1 and 2, respectively. Of the students, $61.9 \%$ identified as White, $13.7 \%$ as Black or African American, $11.2 \%$ as Asian, and $13.2 \%$ as Other/multiracial. The mean age of the students prepolicy was 23.1 years $(\mathrm{SD}=6.4)$ and post-policy 24.3 years $(\mathrm{SD}=6.9)$. Among faculty/staff, $63.0 \%$ identified as White, $9.5 \%$ as Black or African American, $16.0 \%$ as Asian, and $11.6 \%$ as Other/multiracial. The mean age of faculty/staff was 43.9 years $(\mathrm{SD}=13.1)$ and postpolicy 44.2 years $(\mathrm{SD}=13.6)$.

When compared to the student population of the university ( $63 \%$ women), $66.5 \%$ of the student participants were women. Undergraduate students make up $75.7 \%$ of the student population, with the remaining being graduate or professional students. The percentage of undergraduate student participants (compared to graduate students) that completed a survey pre-policy was $77.7 \%$. The percentage of undergraduate student participants was much lower post-policy (59.0\%). When comparing the faculty participants to the overall faculty at the university, $79.4 \%$ of faculty participants identified as White while $70.0 \%$ of the faculty at the university identify as White.

\section{Regression results}

We conducted two linear regression models for both students and faculty/staff, with the following dependent variables as outcomes: 1) attitudes towards tobacco policies (as measured from the Georgia Tobacco Free Colleges and Universities Toolkit) and 2 ) exposure to secondhand smoke. These models allowed us to assess Aims 1 and 2 (i.e. attitudes and secondhand smoke exposure), since we included both pre- and post-policy participants and individual factor variables. For students, cigarette users $(B=-$ $0.70, p<0.01)$, e-cigarette users $(B=-0.49, p<0.01)$ and having friends who smoke cigarettes $(B=-0.13$, $\mathrm{p}<0.01)$ were associated with less positive attitudes towards tobacco policies. Older students $(B=0.01$, 
$\mathrm{p}<0.01)$, female students $(\mathrm{B}=0.23, \mathrm{p}<0.01)$, and nonWhite students $(B=0.11, p<0.05)$ had more positive attitudes towards tobacco policies. Aggregate student attitudes did not differ before and after the policy implementation. For faculty and staff, cigarette users $(B=-0.80, p<0.01)$, e-cigarette users $(B=-0.46$, $\mathrm{p}<0.01)$, non-White employees $(\mathrm{B}=-0.08, \mathrm{p}<0.05)$, and being a staff member $(B=-0.20, p<0.01)$ were associated with less positive attitudes towards tobacco policies. Female faculty/staff $(B=0.20, p<0.01)$ and faculty/staff who completed the survey post-policy implementation $(B=0.10, p<0.01)$ had more positive attitudes towards tobacco policies.

For students, women $(B=0.20, p<0.01)$ reported more exposure to secondhand smoke. Cigarette users $(B=-0.31, p<0.01)$, e-cigarette users $(B=-0.42$, $\mathrm{p}<0.01)$, non-White students $(\mathrm{B}=0.18, \mathrm{p}<0.01)$, and older individuals $(\mathrm{B}=-0.03, \mathrm{p}<0.01)$ reported less

Table 1. Student descriptive statistics

\begin{tabular}{|c|c|c|c|c|}
\hline \multirow[t]{2}{*}{ Variables } & \multicolumn{2}{|c|}{ Pre-policy } & \multicolumn{2}{|c|}{ Post-policy } \\
\hline & $n$ & $\%$ or Mean (SD) & $n$ & $\%$ or Mean (SD) \\
\hline Age (years)* & 631 & $23.07(6.36)$ & 991 & $24.27(6.87)$ \\
\hline \multicolumn{5}{|l|}{ Gender } \\
\hline Men & 191 & 30.27 & 309 & 31.18 \\
\hline Women & 424 & 67.19 & 654 & 65.99 \\
\hline Other/no disclosure & 16 & 2.54 & 28 & 2.83 \\
\hline \multicolumn{5}{|l|}{ Race/ethnicity* } \\
\hline White & 380 & 61.89 & 612 & 62.96 \\
\hline Black or African American & 84 & 13.68 & 92 & 9.47 \\
\hline Asian & 69 & 11.24 & 155 & 15.95 \\
\hline Other/multiracial & 81 & 13.19 & 113 & 11.63 \\
\hline \multicolumn{5}{|l|}{ Year in school* } \\
\hline Freshmen & 114 & 18.07 & 151 & 15.22 \\
\hline Sophomore & 104 & 16.48 & 115 & 11.59 \\
\hline Junior & 131 & 20.76 & 181 & 18.25 \\
\hline Senior & 141 & 22.35 & 138 & 13.91 \\
\hline Graduate student & 141 & 22.35 & 407 & 41.03 \\
\hline \multicolumn{5}{|l|}{ Peer tobacco use } \\
\hline Friends smoke* & 269 & 59.51 & 407 & 52.45 \\
\hline Friends vape & 330 & 73.33 & 549 & 71.48 \\
\hline \multicolumn{5}{|l|}{ User status and attitudes } \\
\hline Current cigarette user* & 67 & 12.12 & 71 & 8.04 \\
\hline Current e-cigarette user & 131 & 21.27 & 173 & 17.82 \\
\hline $\begin{array}{l}\text { Prohibit cigarettes everywhere or allow in designated } \\
\text { areas only* }\end{array}$ & 392 & 84.48 & 729 & 92.63 \\
\hline $\begin{array}{l}\text { Prohibit e-cigarettes everywhere or allow in designated } \\
\text { areas only* }\end{array}$ & 303 & 65.58 & 610 & 77.41 \\
\hline Would you try to stop friends from smoking? & 351 & 78.70 & 615 & 79.56 \\
\hline Would you try to stop friends from vaping?* & 270 & 60.40 & 537 & 69.92 \\
\hline Positive attitudes towards tobacco policies* & 439 & $4.17(0.84)$ & 770 & $4.28(0.79)$ \\
\hline Level of secondhand exposure* & 574 & $3.11(1.08)$ & 906 & $2.72(0.98)$ \\
\hline
\end{tabular}

$\mathrm{N}$ for each response varies from 439 to 631 for pre-policy and 770 to 991 for post-policy. The policy was implemented in July 2019 , with survey assessment occurring three months before and seven months after the policy. For 'Prohibit cigarettes/e-cigarettes everywhere or allow in designated areas only', this number includes participants who selected 'Prohibit use indoors and outdoors at all times', 'Prohibit use indoors; Allow use outdoors in specific locations only', and excludes participants who selected 'Prohibit use indoors; Allow use outdoors everywhere', and 'Allow use indoors and outdoors everywhere.' 'Positive attitudes towards tobacco policies' is the composite score of the five attitude items. Level of secondhand exposure is the one-item assessment of exposure: 'When I am on campus, I am exposed to secondhand smoke'. T-tests were conducted to determine if age, positive attitudes towards tobacco policies, and level of secondhand exposure differed pre- and post-policy. Chi-squared tests were conducted to determine if gender, race/ ethnicity, and year in school differed pre- and post-policy. Two proportion Z-tests were conducted to determine if friends smoke, friends vape, current cigarette/e-cigarette user, prohibit cigarettes/e-cigarettes everywhere or allow in designated areas only, 'Would you try to stop friends from smoking?' and 'Would you try to stop friends from vaping?' differed pre- and post-policy. ${ }^{*}$ Significant differences, $\mathrm{p}<0.05$. 
exposure to secondhand smoke. Most importantly, students after the policy implementation reported less exposure to secondhand smoke $(B=-0.36$, $\mathrm{p}<0.01)$. For faculty/staff, cigarette users $(B=-0.20$, $\mathrm{p}<0.05)$, e-cigarette users $(B=-0.43, p<0.01)$, and older individuals $(B=-0.01, p<0.01)$ reported less exposure to secondhand smoke. Women $(B=0.10$, $\mathrm{p}<0.01)$ and staff $(\mathrm{B}=0.14, \mathrm{p}<0.01)$ reported more exposure to secondhand smoke. Exposure to secondhand smoke did not differ before and after the policy implementation for faculty/staff. Table 3 provides the results of the linear regression models.

To assess change in support of a tobacco-free campus, we conducted two logistic linear regression models with the following outcome variables: 1) prohibit cigarette use inside and outside at all times or only allow in designated areas and 2) e-cigarette use inside and outside at all times or only allow in designated areas. These models allowed us to assess Aims 1 and 2 (i.e. support for tobacco bans), since we included both pre- and post-policy participants and individual factor variables.

The first set of models examined support for cigarette bans. For students, support for a cigarette ban was higher after the policy $(\mathrm{OR}=2.22, \mathrm{p}<0.01)$, and among non-White students $(\mathrm{OR}=2.33, \mathrm{p}<0.01)$ and women $(\mathrm{OR}=2.86, \mathrm{p}<0.01)$, but lower among cigarette users $(\mathrm{OR}=0.17, \mathrm{p}<0.01)$, e-cigarette users $(\mathrm{OR}=0.45, \mathrm{p}<0.01)$, and having friends who smoke cigarettes $(\mathrm{OR}=0.39, \mathrm{p}<0.01)$. For faculty/staff, support for a cigarette ban was higher after the policy $(\mathrm{OR}=2.40, \mathrm{p}<0.01)$ and among women $(\mathrm{OR}=1.93$, $\mathrm{p}<0.01$ ), but lower among current cigarette users $(\mathrm{OR}=0.13, \mathrm{p}<0.01)$, staff $(\mathrm{OR}=0.50, \mathrm{p}<0.01)$, and

\section{Table 2. Faculty and staff descriptive statistics}

\begin{tabular}{|c|c|c|c|c|}
\hline \multirow[t]{2}{*}{ Variables } & \multicolumn{2}{|c|}{ Pre-policy } & \multicolumn{2}{|c|}{ Post-policy } \\
\hline & $n$ & $\%$ or Mean (SD) & $n$ & \% or Mean (SD) \\
\hline Age (years) & 1307 & $43.86(13.11)$ & 556 & $44.22(13.57)$ \\
\hline \multicolumn{5}{|l|}{ Gender } \\
\hline Men & 453 & 33.93 & 215 & 37.85 \\
\hline Women & 839 & 62.85 & 340 & 59.86 \\
\hline Other/no disclosure & 43 & 3.22 & 13 & 2.29 \\
\hline \multicolumn{5}{|l|}{ Race/ethnicity } \\
\hline White & 960 & 73.00 & 418 & 75.04 \\
\hline Black or African American & 202 & 15.36 & 75 & 13.46 \\
\hline Asian & 64 & 4.87 & 31 & 5.57 \\
\hline Other/multiracial & 89 & 6.77 & 33 & 5.92 \\
\hline \multicolumn{5}{|l|}{ Employee classification } \\
\hline Faculty & 452 & 33.76 & 188 & 33.10 \\
\hline Staff & 887 & 66.24 & 380 & 66.90 \\
\hline \multicolumn{5}{|l|}{ User status and attitudes } \\
\hline Current cigarette user & 73 & 6.37 & 30 & 6.45 \\
\hline Current e-cigarette user & 46 & 3.52 & 17 & 3.06 \\
\hline $\begin{array}{l}\text { Prohibit cigarettes everywhere or allow in designated } \\
\text { areas only* }\end{array}$ & 1036 & 91.28 & 456 & 95.40 \\
\hline $\begin{array}{l}\text { Prohibit e-cigarettes everywhere or allow in designated } \\
\text { areas only* }\end{array}$ & 960 & 85.03 & 432 & 91.33 \\
\hline Positive attitudes towards tobacco policies* & 1111 & $4.35(0.75)$ & 472 & $4.44(0.69)$ \\
\hline Level of secondhand exposure & 1244 & $2.51(0.92)$ & 520 & $2.44(0.93)$ \\
\hline
\end{tabular}


non-White employees $(\mathrm{OR}=0.59, \mathrm{p}<0.05)$.

The second set of models examined support for e-cigarette bans. For students, support for an e-cigarette ban was higher after the policy $(\mathrm{OR}=1.64$, $\mathrm{p}<0.01)$ and among women $(\mathrm{OR}=1.83, \mathrm{p}<0.01)$, older students $(\mathrm{OR}=1.06, \mathrm{p}<0.01)$, and non-White students $(\mathrm{OR}=1.68, \mathrm{p}<0.01)$, but lower among cigarette users $(\mathrm{OR}=0.28, \mathrm{p}<0.01)$, e-cigarette users $(\mathrm{OR}=0.17, \mathrm{p}<0.01)$, having friends who smoke $(\mathrm{OR}=0.60, \mathrm{p}<0.01)$, and having friends who vape $(\mathrm{OR}=0.48, \mathrm{p}<0.01)$. For faculty/staff, support for an e-cigarette ban was higher after the policy $(\mathrm{OR}=2.36, \mathrm{p}<0.01)$ and among women $(\mathrm{OR}=2.31$, $\mathrm{p}<0.01)$, but lower among cigarette users $(\mathrm{OR}=0.19$, $\mathrm{p}<0.01)$, e-cigarette users $(\mathrm{OR}=0.14, \mathrm{p}<0.01)$, and staff $(\mathrm{OR}=0.54, \mathrm{p}<0.01)$. Table 4 includes the results of the logistic regression models for support.

We conducted a set of student-specific logistic regression models to assess Aim 3, with the following outcomes: 1) willingness to stop friends from

\section{Table 3. Linear regression results}

\begin{tabular}{|c|c|c|c|c|}
\hline \multirow[t]{2}{*}{ Predictor variables } & \multicolumn{2}{|c|}{ Attitudes } & \multicolumn{2}{|c|}{ Secondhand exposure } \\
\hline & Students & Faculty/staff & Students & Faculty/staff \\
\hline & B (SE) & $B(\mathrm{SE})$ & $B(S E)$ & $B(\mathrm{SE})$ \\
\hline Intercept & $4.08(0.11)^{* *}$ & $4.40(0.08)^{* *}$ & $3.82(0.16)^{* *}$ & $3.03(0.11)^{* *}$ \\
\hline Post-policy (Ref. pre-policy) & $0.03(0.05)$ & $0.10(0.04)^{* *}$ & $-0.36(0.06)^{* *}$ & $-0.09(0.05)$ \\
\hline Current cigarette user & $-0.70(0.08)^{* *}$ & $-0.80(0.08)^{* *}$ & $-0.31(0.11)^{* *}$ & $-0.20(0.10)^{*}$ \\
\hline Current e-cigarette user & $-0.49(0.07)^{* *}$ & $-0.46(0.12)^{* *}$ & $-0.42(0.09)^{* *}$ & $-0.43(0.15)^{* *}$ \\
\hline Female (Ref. male) & $0.23(0.05)^{* *}$ & $0.20(0.04)^{* *}$ & $0.20(0.07)^{* *}$ & $0.10(0.05)^{*}$ \\
\hline Age (years) & $0.01(0.00)^{*}$ & $0.00(0.00)$ & $-0.03(0.00)^{* *}$ & $-0.01(0.00)^{* *}$ \\
\hline Race (Ref: White) & $0.11(0.05)^{*}$ & $-0.08(0.04)^{*}$ & $0.18(0.06)^{* *}$ & $-0.02(0.05)$ \\
\hline Friends who smoke & $-0.13(0.05)^{* *}$ & & $-0.02(0.07)$ & \\
\hline Friends who vape & $-0.08(0.05)$ & & $-0.00(0.07)$ & \\
\hline Staff (Ref. faculty) & & $-0.20(0.04)^{* *}$ & & $0.14(0.05)^{* *}$ \\
\hline $\mathrm{R}^{2}$ & 0.22 & 0.15 & 0.11 & 0.07 \\
\hline
\end{tabular}

${ }^{*} \mathrm{p}<0.05{ }^{* *} \mathrm{p}<0.01$. 'Post-policy' is coded with pre-policy as the reference. 'Current cigarette user' is coded with non-current cigarette user as the reference. 'Current e-cigarette user' is coded with non-current e-cigarette user as the reference. 'Female' is coded with male as the reference. 'Age' is continuous. 'Race' is coded with White as the reference. 'Friends smoke' is coded with not having friends who smoke cigarettes as the reference. 'Friends who vape' is coded with not having friends who vape as the reference. 'Staff' is coded with faculty as the reference.

\section{Table 4. Logistic regression results of support of cigarette and e-cigarette bans}

\begin{tabular}{lcccc} 
Predictor variables & \multicolumn{2}{c}{ Cigarette ban } & & E-cigarette ban \\
& \multicolumn{1}{c}{ Students } & Faculty/staff & Students & Faculty/staff \\
& OR $(95 \% \mathrm{CI})$ & OR $(95 \% \mathrm{CI})$ & OR $(95 \% \mathrm{CI})$ & OR $(95 \% \mathrm{CI})$ \\
\hline Intercept & $5.50(1.51-19.47)^{* *}$ & $25.62(9.10-74.64)^{* *}$ & $1.11(0.41-2.94)$ & $6.13(2.76-13.78)^{* *}$ \\
Post-policy (Ref. pre-policy) & $2.22(1.38-3.60)^{* *}$ & $2.40(1.34-4.58)^{* *}$ & $1.64(1.17-2.28)^{* *}$ & $2.36(1.51-3.83)^{* *}$ \\
Current cigarette user & $0.17(0.10-0.30)^{* *}$ & $0.13(0.07-0.23)^{* *}$ & $0.28(0.16-0.50)^{* *}$ & $0.19(0.11-0.31)^{* *}$ \\
Current e-cigarette user & $0.45(0.26-0.80)^{* *}$ & $0.63(0.21-2.46)$ & $0.17(0.11-0.26)^{* *}$ & $0.14(0.06-0.33)^{* *}$ \\
Female (Ref. male) & $2.86(1.77-4.65)^{* *}$ & $1.93(1.21-3.10)^{* *}$ & $1.83(1.30-2.58)^{* *}$ & $2.31(1.60-3.33)^{* *}$ \\
Age (years) & $1.02(0.98-1.06)$ & $0.99(0.98-1.01)$ & $1.06(1.03-1.10)^{* *}$ & $1.01(0.99-1.02)$ \\
Race (Ref. White) & $2.33(1.33-4.27)^{* *}$ & $0.59(0.37-0.96)^{*}$ & $1.68(1.18-2.40)^{* *}$ & $0.72(0.49-1.08)$ \\
Friends who smoke & $0.39(0.20-0.71)^{* *}$ & & $0.60(0.40-0.82)^{* *}$ & \\
Friends who vape & $1.20(0.61-2.30)$ & & $0.48(0.29-0.75)^{* *}$ & \\
Staff (Ref. faculty) & & $0.50(0.28-0.86)^{* *}$ & & $0.54(0.35-0.82)^{* *}$ \\
AIC & 506.46 & 570.30 & 935.21 & 837.77
\end{tabular}

${ }^{*} \mathrm{p}<0.05,{ }^{* *} \mathrm{p}<0.01$. 'Post-policy' is coded with pre-policy as the reference. 'Current cigarette user' is coded with non-current cigarette user as the reference. 'Current e-cigarette user' is coded with non-current e-cigarette user as the reference. 'Female' is coded with male as the reference. 'Age' is continuous. 'Race' is coded with White as the reference. 'Friends smoke' is coded with not having friends who smoke cigarettes as the reference. 'Friends who vape' is coded with not having friends who vape as the reference. 'Staff' is coded with faculty as the reference. 
smoking cigarettes and 2) willingness to stop friends from vaping. Students who were cigarette users $(\mathrm{OR}=0.19, \mathrm{p}<0.01)$ and had friends who smoked cigarettes $(\mathrm{OR}=0.38, \mathrm{p}<0.01)$ were less likely to try to stop their friends from smoking cigarettes. Women were more likely $(\mathrm{OR}=1.79, \mathrm{p}<0.01)$ to try to stop their friends from smoking cigarettes. When asked about stopping friends who vape, students who were cigarette users $(\mathrm{OR}=0.38, \mathrm{p}<0.01)$, e-cigarette users $(\mathrm{OR}=0.40, \mathrm{p}<0.01)$, had friends who smoked cigarettes $(\mathrm{OR}=0.54, \mathrm{p}<0.01)$, and had friends who vaped $(\mathrm{OR}=0.48, \mathrm{p}<0.01)$ were less likely to stop their friends. Women $(\mathrm{OR}=2.07, \mathrm{p}<0.01)$ and students who completed the survey post-policy $(\mathrm{OR}=1.45, \mathrm{p}<0.05)$ were more likely to stop their friends from vaping. Table 5 includes the logistic regression model results.

\section{Table 5. Logistic regression results of student willingness to stop friends from smoking cigarettes and vaping}

\begin{tabular}{lcc} 
Predictor variables & \multicolumn{1}{c}{ Stop smoking } & Stop vaping \\
& OR $(95 \%$ CI $)$ & OR $(95 \%$ CI $)$ \\
\hline Intercept & $11.36(4.93-26.46)^{* *}$ & $3.18(1.49-6.79)^{* *}$ \\
Post-policy & $0.92(0.64-1.30)$ & $1.45(1.09-1.95)^{*}$ \\
(Ref. pre-policy) & & \\
Current cigarette user & $0.19(0.11-0.31)^{* *}$ & $0.38(0.23-0.63)^{* *}$ \\
Current e-cigarette user & $1.09(0.68-1.76)$ & $0.40(0.27-0.58)^{* *}$ \\
Female (Ref. male) & $1.79(1.28-2.51)^{* *}$ & $2.07(1.54-2.79)^{* *}$ \\
Age (years) & $0.98(0.96-1.01)$ & $1.00(0.98-1.02)$ \\
Race (Ref. White) & $1.21(0.85-1.74)$ & $1.19(0.88-1.61)$ \\
Friends who smoke & $0.38(0.25-0.56)^{* *}$ & $0.54(0.39-0.74)^{* *}$ \\
Friends who vape & $0.89(0.57-1.37)$ & $0.48(0.33-0.71)^{* *}$ \\
AIC & 921.85 & 1160.10
\end{tabular}

${ }^{*} p<0.05,{ }^{* *} p<0.01$. 'Post-policy' is coded with pre-policy as the reference. 'Current cigarette user' is coded with non-current cigarette user as the reference. 'Current e-cigarette user' is coded with non-current e-cigarette user as the reference. 'Female' is coded with male as the reference. 'Age' is continuous. 'Race' is coded with White as the reference. 'Friends smoke' is coded with not having friends who smoke cigarettes as the reference. 'Friends who vape' is coded with not having friends who vape as the reference. 'Staff' is coded with faculty as the reference.

\section{DISCUSSION}

Overall, there was an increase in positive attitudes and support for tobacco policies to reduce use and exposure to tobacco products on college campus after implementation of the tobacco-free policy. Among both students and faculty/staff, cigarette and e-cigarette users were less supportive of tobacco free policies and had fewer positive attitudes towards tobacco and e-cigarette bans. Moreover, women in both samples were more supportive and had more positive attitudes towards the policies. These findings generally corroborate earlier research that have found differences based on gender and tobacco product use status $9,15,16,19$. Older students had more positive attitudes towards tobacco policies and were supportive of an e-cigarette ban, which supports older individuals being more supportive of tobacco policies ${ }^{17,18}$.

However, findings between students and faculty/staff were less consistent by race/ethnicity. Specifically, non-White students tended to be in support of tobacco bans and had more positive attitudes towards tobacco policies, while non-White employees were less supportive of tobacco bans and had less positive attitudes towards tobacco policies. It is unclear why non-White students differed from nonWhite employees in their support and attitudes, but prior research has been inconsistent when assessing racial differences ${ }^{23,24}$. Additionally, attitudes towards tobacco policies did not improve for students but did for faculty and staff. Prior research has found it can take time for attitudes towards policies to change ${ }^{10}$.

Among students, having friends who smoked cigarettes is a strong influence. In our sample, it predicted attitudes, support of tobacco bans, and willingness to approach friends using tobacco products. Thus, those who were around friends who smoked did not highly support the tobacco policies or did not feel comfortable approaching friends who smoked, even if they themselves did not smoke. It is possible even if students saw the benefit of the policies, they experienced cognitive dissonance (i.e. experiencing inconsistent attitudes or beliefs that lead to discomfort and is resolved by changing one's attitudes or beliefs). For example, they might think that since they have friends who smoke, they must be against policy restrictions, even if they do not smoke. When considering having friends who vape, this variable was only significant when the outcome was e-cigarette specific. Perhaps being around those who vape makes students indifferent towards cigarette use and they only experience cognitive dissonance when considering outcomes related to e-cigarettes.

When considering differences between faculty and staff, staff were less supportive of the tobacco bans and held fewer positive attitudes towards tobacco policies. There are many underlying factors that could explain this difference, such as education or income. 
Education level has been shown to be associated with tobacco use and understanding the health risks associated with tobacco product use ${ }^{25}$. Educational degree was not included among the demographic questions, but faculty and staff could have differed in their educational attainment. However, this is only speculation as other unmeasured factors could have influenced this difference.

Finally, students reported lower secondhand exposure after policy implementation, but there was no change reported by faculty and staff. Cigarette and e-cigarette users both reported lower levels of secondhand exposure. Perhaps cigarette and e-cigarette users know they contribute to secondhand exposure, but to reduce those negative feelings, they downplay the level of secondhand smoke in the environment. Research has also shown smokers have lower risk perceptions of secondhand smoke $^{26}$, which could have influenced their response. In both samples, women reported higher exposure to secondhand smoke. Prior research findings have been inconsistent, with women ${ }^{27}$ and men $^{28}$ both reporting higher exposure to secondhand smoke. Thus, this finding should be interpreted with caution given inconsistencies across the literature.

\section{Strengths and limitations}

There are several limitations that should be addressed. Given social desirability bias of self-report measure ${ }^{29}$, the results should be interpreted carefully as participants may have wished to present themselves positively. For variables focused on peer influence or willingness to stop a friend from smoking/vaping, it is not possible to establish causality as the study was cross-sectional. For example, having fewer positive attitudes towards tobacco policies could be the predictor of peer influence as students may gravitate towards others who share their attitudes. Since the pre- and post-policy participants were both completely different cohorts, it was not possible to assess within-person changes. From an intervention standpoint, it might have been useful to assess how a person's attitudes and support for a tobacco policy ban changed post-policy. Additionally, while efforts were made to include data from a representative sample of the university, some demographics, such as student gender, appeared to be representative, while other demographics, such as percentage of undergraduate students during the post-policy survey, were less representative of the university population.

However, there are several strengths that should be emphasized. The sample was not limited to students, but also included faculty and staff, which has not been the case for most prior research focused on university settings. By including participants from all parts of the university, it is much easier to argue generalizability. The sample of participants was quite large not only across students and faculty/ staff samples, but also pre- and post-policy. We also included a wide range of predictors when possible. Although not all predictors were available for faculty and staff, we included several predictors of attitudes and support for students that could be considered peer influence. This expands the literature which has largely only included basic demographic variables or personal tobacco product use.

\section{Future directions}

Future research should include additional follow-up studies. As more members of the community become familiar with the tobacco-free policy, attitudes and support for a ban are likely to further change. This is especially important for e-cigarettes, as it appears a significant proportion of the student population still uses these products, even as growing research examines the possible negative health effects ${ }^{30,31}$. Additionally, future studies should elucidate the psychosocial mechanisms behind why students who do not smoke, but have smoking friends, were less likely to endorse tobacco-free policies. Other outcomes, such as exposure to secondhand smoke, are also likely to change. There was only a significant difference in exposure for students, but over time faculty and staff may report less exposure to secondhand smoke. Given the negative health effects of secondhand smoke exposure $^{32,33}$, it will be important to continue to assess if university members are exposed to smoke and when they are, and which specific locations on campus the exposure occurs. Exposure may be reduced in the central parts of campus, but tobacco users may migrate to the campus boundary to smoke ${ }^{34}$.

\section{CONCLUSIONS}

Although cigarette use is declining, the use of tobacco products and e-cigarettes remains a problem among subsets of the United States population. Adolescence 
and young adulthood are particularly critical periods for development that is associated with engagement in risky health behaviors. Universities can have an influence on the risky health behaviors that college students engage in; therefore, it is important for universities to develop environments in which tobacco products are restricted or completely banned. The current study suggests that both students and faculty/staff had positive attitudes towards tobaccofree policies, and these attitudes became more positive post-policy for faculty/staff. Moreover, support for a ban on cigarettes and e-cigarettes increased postpolicy for both students and faculty/staff. Even though the policy was not universally supported, especially by those who were current tobacco product users, the findings provide evidence that tobacco policies are generally accepted by university members. Therefore, universities should not hesitate to develop policies that target tobacco product use as most university members are likely to support those policies.

\section{REFERENCES}

1. Ramôa CP, Eissenberg T, Sahingur SE. Increasing popularity of waterpipe tobacco smoking and electronic cigarette use: Implications for oral healthcare. J Periodontal Res. 2017;52(5):813-823. doi:10.1111/jre.12458

2. Sullman MJM, Gras ME, Kagialis A, Papageorgi I, FontMayolas S. Cigarette, e-cigarette and waterpipe use among young adults: differential cognitions about these three forms of smoking. Int J Environ Res Public Health. 2020;17(11):3787. doi:10.3390/ijerph17113787

3. Taylor J. Life events and peer substance use and their relation to substance use problems in college students. J Drug Educ. 2006;36(2):179-191. doi:10.2190/1MNH-ARUD-R57K-7710

4. Blake KD, Klein AL, Walpert L, et al. Smoke-free and tobacco-free colleges and universities in the United States. Tob Control. 2020;29(3):289-294. doi:10.1136/tobaccocontrol-2018-054829

5. Dilliott D, Fazel S, Ehsan N, Sibbald SL. The attitudes and behaviors of students, staff and faculty towards smoke-free and tobacco-free campus policies in North American universities: A narrative review. Tob Prev Cessat. 2020;6(August):1-7. doi:10.18332/tpc/125080

6. Lupton J, Townsend J. A systematic review and metaanalysis of the acceptability and effectiveness of university smoke-free policies. J Am Coll Health. 2015;63(4):238247. doi:10.1080/07448481.2015.1015029

7. Trumbo CW, Harper R. Orientation of US Young adults toward e-cigarettes and their use in public. Health Behav Policy Rev. 2015;2(2):163-170. doi:10.14485/HBPR.2.2.8
8. Arshad A, Matharoo J, Arshad E, Sadhra SS, NortonWangford R, Jawad M. Knowledge, attitudes, and perceptions towards waterpipe tobacco smoking amongst college or university students: a systematic review. BMC Public Health. 2019;19(1):439. doi:10.1186/s12889-019-6680-х

9. Bartington SE, Wootton R, Hawkins P, Farley A, Jones LL, Haroon S. Smoking behaviours and attitudes towards campus-wide tobacco control policies among staff and students: a cross-sectional survey at the University of Birmingham. BMC Public Health. 2020;20(1):252. doi:10.1186/s12889-020-8321-9

10. Lechner WV, Meier E, Miller MB, Wiener JL, Fils-Aime Y. Changes in smoking prevalence, attitudes, and beliefs over 4 years following a campus-wide anti-tobacco intervention. J Am Coll Health. 2012;60(7):505-511. doi:10.1080/07448481.2012.681816

11. Gatto A, Powell SE, Walters EF, Zamani S, Sales LB, DeBate R. A mixed-methods assessment of a peerenforced tobacco- and smoke-free policy at a large urban university. J Community Health. 2019;44(2):365-376. doi:10.1007/s10900-018-0593-y

12. Ramachandran S, Bentley S, Casey E, Bentley JP. Prevalence of and factors associated with violations of a campus smoke-free policy: a cross-sectional survey of undergraduate students on a university campus in the USA. BMJ Open. 2020;10(3):e030504. doi:10.1136/bmjopen-2019-030504

13. Zaleski AC, Aloise-Young PA. Using peer injunctive norms to predict early adolescent cigarette smoking intentions. J Appl Soc Psychol. 2013;43(Suppl 1):E124-E131. doi:10.1111/jasp.12080

14. Forden CL, Carrillo AM. Smoking and attitudes toward smoking policy at a University in Egypt. J Ethn Subst Abuse. 2016;15(4):329-345. doi:10.1080/15332640.2015.1066288

15. Braverman MT, Hoogesteger LA, Johnson JA. Predictors of support among students, faculty and staff for a smokefree university campus. Prev Med. 2015;71:114-120. doi:10.1016/j.ypmed.2014.12.018

16. Cooper TV, Cabriales JA, Hernandez N, Law J. A baseline assessment of attitudes toward tobacco free campus policies in a U.S./México border university. Addict Behav. 2016;60:223-227. doi:10.1016/j.addbeh.2016.04.023

17. Ickes MJ, Butler K, Wiggins AT, Rayens MK, Hahn EJ. Support for Tobacco 21 in a tobacco-growing state. West J Nurs Res. 2019;41(8):1203-1215. doi:10.1177/0193945918822523

18. Borland R, Yong HH, Siahpush M, et al. Support for and reported compliance with smoke-free restaurants and bars by smokers in four countries: findings from the International Tobacco Control (ITG) Four Country Survey. Tob Control. 2006;15(Suppl 3):iii34-iii41. doi:10.1136/tc.2004.008748

19. Do EK, Fallavollita WL, Bonat B, Fugate-Laus K, Rossi BC, Fuemmeler BF. Student Attitudes Toward Tobacco Use and Tobacco Policies on College Campuses. J Community Health. 
2020;45(4):751-760. doi:10.1007/s10900-020-00790-3

20. Harris PA, Taylor R, Thielke R, Payne J, Gonzalez N, Conde JG. Research electronic data capture (REDCap)-a metadata-driven methodology and workflow process for providing translational research informatics support. J Biomed Inform. 2009;42(2):377-381. doi:10.1016/j.jbi.2008.08.010

21. Harris PA, Taylor R, Minor BL, et al. The REDCap consortium: Building an international community of software platform partners. J Biomed Inform. 2019;95:103208. doi:10.1016/j.jbi.2019.103208

22. Jefferson CL. Georgia Tobacco-Free Colleges \& Universities Toolkit. 2nd Ed. Georgia Department of Public Health; 2014. Accessed December 19, 2019. https://dph.georgia.gov/sites/dph.georgia.gov/files/ related_files/site_page/Tobacco $\% 20$ Free $\% 20$ Colleges $\% 20$ and\%20Universities\%20Tool\%20kit\%20June\%202014.pdf

23. Ling PM, Neilands TB, Glantz SA. Young adult smoking behavior: a national survey. Am J Prev Med. 2009;36(5):389394.e2. doi:10.1016/j.amepre.2009.01.028

24. Kelly BC, Weiser JD, Parsons JT. Smoking and attitudes on smoke-free air laws among club-going young adults. Soc Work Public Health. 2009;24(5):446-453. doi:10.1080/19371910802678715

25. Jamal A, Phillips E, Gentzke AS, et al. Current Cigarette Smoking Among Adults - United States, 2016. MMWR Morb Mortal Wkly Rep. 2018;67(2):53-59. doi:10.15585/mmwr.mm6702a1

26. Lonergan BJ, Meaney S, Perry IJ, et al. Smokers still underestimate the risks posed by secondhand smoke: a repeated cross-sectional study. Nicotine Tob Res. 2014;16(8):1121-1128. doi:10.1093/ntr/ntu046

27. Wolfson M, McCoy TP, Sutfin EL. College students' exposure to secondhand smoke. Nicotine Tob Res. 2009;11(8):977-984. doi:10.1093/ntr/ntp100

28. Filippidis FT, Agaku IT, Girvalaki C, et al. Relationship of secondhand smoke exposure with sociodemographic factors and smoke-free legislation in the European Union. Eur J Public Health. 2016;26(2):344-349. doi:10.1093/eurpub/ckv204

29. Latkin CA, Edwards C, Davey-Rothwell MA, Tobin KE. The relationship between social desirability bias and self-reports of health, substance use, and social network factors among urban substance users in Baltimore, Maryland. Addict Behav. 2017;73:133-136. doi:10.1016/j.addbeh.2017.05.005

30. Glynos C, Bibli SI, Katsaounou P, et al. Comparison of the effects of e-cigarette vapor with cigarette smoke on lung function and inflammation in mice. Am J Physiol Lung Cell Mol Physiol. 2018;315(5):L662-L672. doi:10.1152/ajplung.00389.2017

31. Skotsimara G, Antonopoulos AS, Oikonomou E, et al. Cardiovascular effects of electronic cigarettes: A systematic review and meta-analysis. Eur J Prev Cardiol. 2019;26(11):1219-1228. doi:10.1177/2047487319832975

32. Kim AS, Ko HJ, Kwon JH, Lee JM. Exposure to secondhand smoke and risk of cancer in never amokers: a meta-analysis of epidemiologic studies. Int J Environ Res Public Health. 2018;15(9):1981. doi:10.3390/ijerph15091981

33. Diver WR, Jacobs EJ, Gapstur SM. Secondhand smoke exposure in childhood and adulthood in relation to adult mortality among never smokers. Am J Prev Med. 2018;55(3):345-352. doi:10.1016/j.amepre.2018.05.005

34. Braverman MT, Geldhof GJ, Hoogesteger LA, Johnson JA. Predicting students' noncompliance with a smoke-free university campus policy. Prev Med. 2018;114:209-216. doi:10.1016/j.ypmed.2018.07.002

ACKNOWLEDGEMENTS

The authors would like to acknowledge Kendall Fugate-Laus at VCU and Westley Fallavollita (now at the University of Virginia) for their work testing/developing the pre- and post-policy survey instruments. We would like to acknowledge Jason Burkett from the Survey Evaluation and Research Laboratory of the L. Wilder School at VCU, who assisted with collecting the survey data for this research project. We thank Erica Sheldon Heath, Amy Nyman, Amelia Jazwa, and Saiza Jivani from the Georgia State University School of Public Health, who assisted with survey measure design, and Bidisha Sinha (formerly of ACS-TFGCI) for her assistance in coordinating efforts.

\section{CONFLICTS OF INTEREST}

The authors have each completed and submitted an ICMJE form for disclosure of potential conflicts of interest. The authors declare that they have no competing interests, financial or otherwise, related to the current work. All authors report grants from American Cancer Society Tobacco Free Generation Campus Initiative (ACS-TFGCI), supported by CVS Health Foundation, NIH-NCI Cancer Center Support Grant P30 CA016059, REDCap electronic data capture tools hosted at Virginia Commonwealth University (Award Number UL1TR002649), related to the current work. T. E. Glasgow also reports National Institute of General Medical Sciences K12 award (2K12GM093857-09), and C. A. Miller also reports National Cancer Institute T32 award (2T32CA093423).

\section{FUNDING}

The research was funded with a grant awarded to the research group by the American Cancer Society's (ACS) Tobacco Free Generation Campus Initiative (TFGCI), supported by the CVS Health Foundation. Additional support was provided from NIH-NCI Cancer Center Support Grant P30 CA016059. Study data were collected and managed using REDCap electronic data capture tools hosted at Virginia Commonwealth University (Award Number UL1TR002649). This study was also supported in part by a National Institute of General Medical Sciences K12 award (2K12GM093857-09) to T.E. Glasgow and a National Cancer Institute T32 award (2T32CA093423) to C.A. Miller.

\section{ETHICAL APPROVAL AND INFORMED CONSENT}

The study procedures were determined to be exempt from the university's Institutional Review Board, provided the data were collected anonymously from participants.

\section{DATA AVAILABILITY}

The data supporting this research is available from the authors on reasonable request.

\section{PROVENANCE AND PEER REVIEW}

Not commissioned; externally peer reviewed. 